\title{
Achalasia: treatment, current status and future advances
}

\author{
Lee L. Swanström ${ }^{1,2}$
}

${ }^{1}$ Division of Surgery, Oregon Health Sciences University, Portland, OR, USA; ${ }^{2} \mathrm{IHU}$-Strasbourg, Strasbourg, France

Received: December 8, 2018 Accepted: February 10, 2019

\section{Correspondence to}

Lee L. Swanström, M.D.

Division of Surgery, Oregon

Health Sciences University, 4805

Northeast Glisan, 6N6o, Port-

land, OR 97213, USA

Tel: +1-336-51080361

Fax: +1-333-88119099

E-mail: Lee.swanstrom@

ihu-strasbourg.eu
Achalasia was first described in the 17th century and its treatment continues to be challenging. Palliative treatment involves disruption of the lower esophageal sphincter, which can be accomplished mechanically (balloon dilation or surgical myotomy) or chemically (Botox). True surgical treatment originated some 100 years ago and remained largely unchanged until the advent of thoracoscopic and then laparoscopic myotomy beginning in the 1980 s. Because these procedures provided relatively definitive treatment and were well tolerated by patients, minimal invasive surgery assumed a primary role in the treatment algorithms for achalasia. In 2008, an endoscopic (incision-less) myotomy approach, per-oral endoscopic myotomy, was described. This even less invasive approach has rapidly been adopted in the majority of high-volume achalasia centers. Newer interventions, such as stenting and cell transplant, are under active investigation.

Keywords: Achalasia; Myotomy; Per-oral endoscopic myotomy; Endoscopy; Laparoscopy

\section{INTRODUCTION}

Achalasia was first described by Thomas Willis in 1674 [1]. A Greek term, achalasia literally means "non-relaxing" and refers to the dysfunctional lower esophageal sphincter (LES). As an incurable disease, the treatment of achalasia has always been palliative, aimed at relieving the solid food dysphagia that is the hallmark symptom. Secondary endpoints of treatment include the reversal of weight loss and the arrest of progressive esophageal dilation. In patients with end-stage achalasia, treatment may be directed toward the prevention of chronic aspiration.

Achalasia is a rare disease. The population incidence of idiopathic achalasia is estimated to be 1:100,000 and is remarkably consistent geographically. There is a bimodal age distribution, with most patients in the 20 to 40 and 60 to 70 age groups [2]. Achalasia related to Chagas disease is regionally endemic throughout Central and South America and associated with the presence of the parasite (Trypanosoma cruzi) vector, the reduviid beetle [3]. Public health policy and early parasite treatment have dramatically decreased the number of Chagas-disease-related achalasia cases worldwide, but this form of the disease remains a problem in poorer rural areas.

The etiology of achalasia is poorly understood despite $>200$ years of investigation. An exception is the primary dysmotility resulting from infection with $\mathrm{T}$. cruzi, as mentioned above [4]. Chagas disease is a multi-organ condition, the esophageal manifestations of which have a manometry profile similar to that of standard achalasia, i.e., no primary peristalsis in the esophageal body and a non-relaxing LES. There is also an extremely rare genetically linked form of achalasia that is associated with severe genetic abnormalities such as triple A syndrome [5]. According to current thinking, achalasia is probably an autoimmune disorder, perhaps a cross-immune reaction against herpes simplex virus or other vi- 
Table 1. Eckhardt score system

\begin{tabular}{lcccc}
\hline \multirow{2}{*}{ Score } & \multicolumn{3}{c}{ Symptom } \\
\cline { 2 - 5 } & Weight loss, kg & Dysphagia & Retrosternal pain & Regurgitation \\
\hline 0 & None & None & None & None \\
1 & $<5$ & Occasional & Occasional & Occasional \\
2 & $5-10$ & Daily & Daily & Daily \\
3 & $>10$ & Each meal & Each meal & Each meal \\
\hline
\end{tabular}

ruses [6]. Regardless of the etiology, once aperistalsis is established it is not reversible by any currently available treatment, although there are anecdotal reports of vestigial primary peristaltic contractions following a peroral endoscopic myotomy (POEM) procedure [7]. Nonetheless, most forms of treatment result in a substantial palliation of symptoms in the majority of patients, allowing them to resume a more or less normal diet, sustain their weight and avoid the progressive dilation that eventually leads to esophagectomy or death from aspiration.

\section{DIAGNOSTICS}

Achalasia is diagnosed based on the clinical symptoms and the results of imaging and physiology studies. Symptoms almost universally include solid food dysphagia, with associated symptoms of regurgitation, chest pain and heartburn. Weight loss, once a uniform component of achalasia presentation, is more variable today due to the widespread availability of high-calorie liquid foods. Because many achalasia patients complain of symptoms mimicking those of gastroesophageal reflux disease (GERD), especially heartburn reflux, they are often erroneously diagnosed with GERD and treated accordingly. However, these symptoms are most likely related to esophageal stasis and not to gastro-esophageal reflux, as the LES is non-relaxing. Chest pain is also a highly variable and non-specific symptom and may be from other sources, such as cardiac disease, or other esophageal spastic disorders, such as diffuse esophageal spasm. Achalasia symptoms are routinely quantified by the Eckhardt score [8], which, while not truly validated as a quantitative score, is widely used in the follow-up of patients and is an important assess-

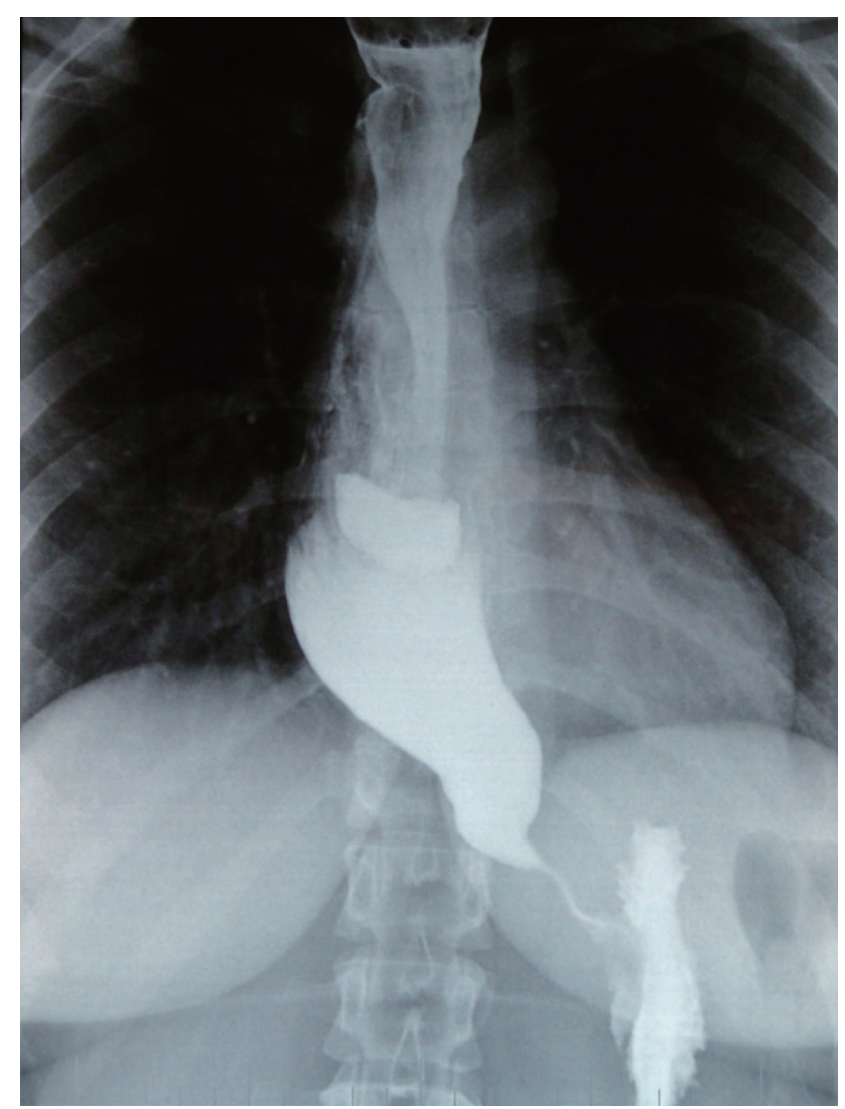

Figure 1. Pathognomonic X-ray image of achalasia.

ment tool in this chronic, non-curable disease (Table 1). Imaging studies provide a nearly pathognomonic test. Typical findings include esophageal body dilation with distal smooth narrowing at the LES ("birds beak" deformity) (Fig. 1). A contrast X-ray, if available at the hospital's facilities, can also serve as a quantitative follow-up tool. In a "timed barium swallow," the patient, in an upright position, is given a standardized quantity of barium, after which still images are obtained at set intervals $(5,10,15$ minutes). The height of the retained barium column at each interval is the metric, with a 
normal esophagus clearing the barium dose by $5 \mathrm{~min}$ utes (Fig. 2).

Patients with achalasia who complain of GERD symptoms typically undergo 24 -hour $\mathrm{pH}$ testing, but the test results are difficult to interpret as they are often positive due to the stasis and fermentation associated with achalasia. Therefore, the test is not diagnostically useful, as achalasia patients almost never have true GERD and, even if they did, their treatment options would not change substantially.

The most critical diagnostic test is esophageal manometry and, in particular, high-resolution manometry (HRM). In fact, the very definition of achalasia is based on the manometry criteria: a complete absence

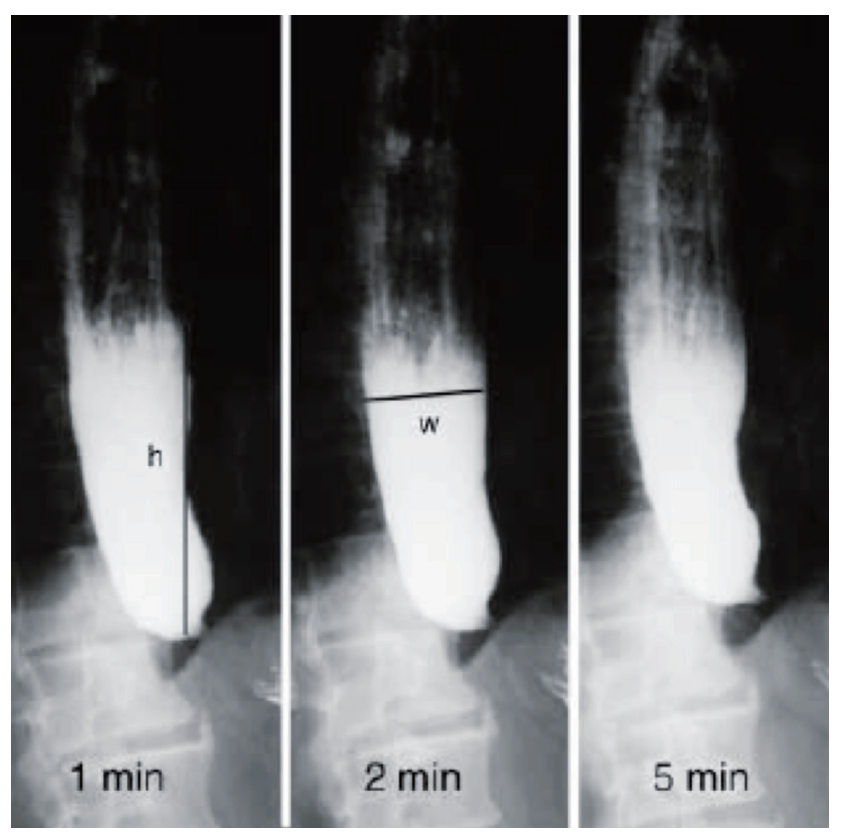

Figure 2. Timed barium swallow showing achalasia. of progressive primary peristaltic contractions and an incompletely relaxing LES (not a hypertensive LES as once described, as the LES can be hypertensive, normotensive or even hypotensive). Since early 2000 , the large volume of data collected by HRM has contributed to a further understanding of achalasia and has led to the development of the Chicago classification scheme, which separates achalasia into types I, II, III [9]. In type I, there is a complete absence of esophageal contractions, in type II simultaneous pressurization, and in type III high-pressure non-peristaltic body contractions (Fig. 3). Moreover, the Chicago classification correlates with treatment outcome, as different success rates can be expected in the treatment of disease with different classifications $[10]$.

\section{TREATMENTS}

Currently, there are several relatively good palliative treatments for achalasia, each with its advantages and disadvantages, and a place in the treatment algorithm.

\section{Botox}

The injection of botulinum toxin into the LES has been a popular form of palliation since it was first described by Pasricha et al. [11], in 1993. The typical treatment regime is the injection of 100 units of reconstituted Botox, divided into four aliquots, into the LES in four quadrants. This can also be done under endoscopic ultrasound visualization, even though there is no convincing evidence that it improves outcome. While Botox is safe, relatively effective $(80 \%$ early dysphagia relief) and minimally invasive, it has two major draw-

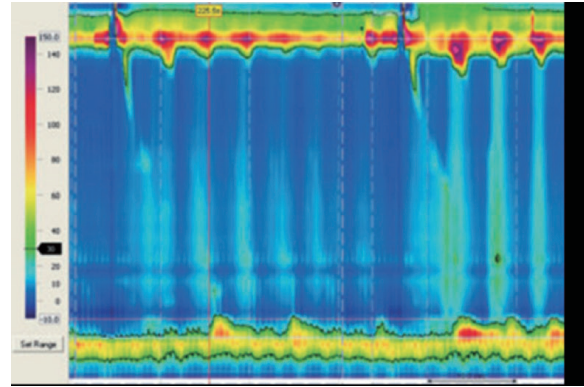

A

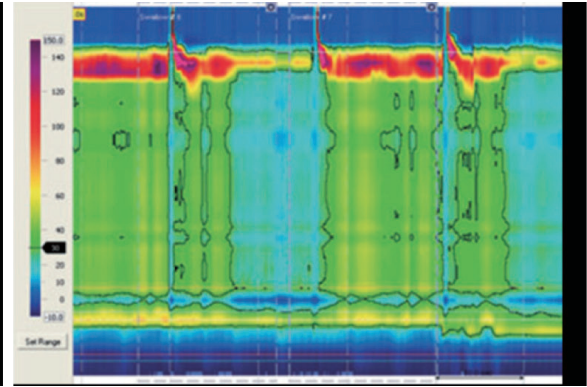

B

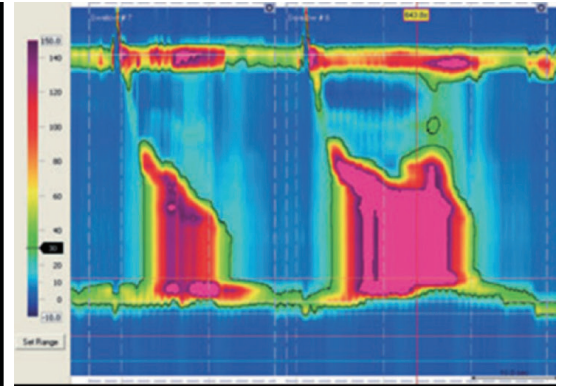

C

Figure 3. (A) Chicago type I achalasia, (B) Chicago type II achalasia, and (C) Chicago type III achalasia. 


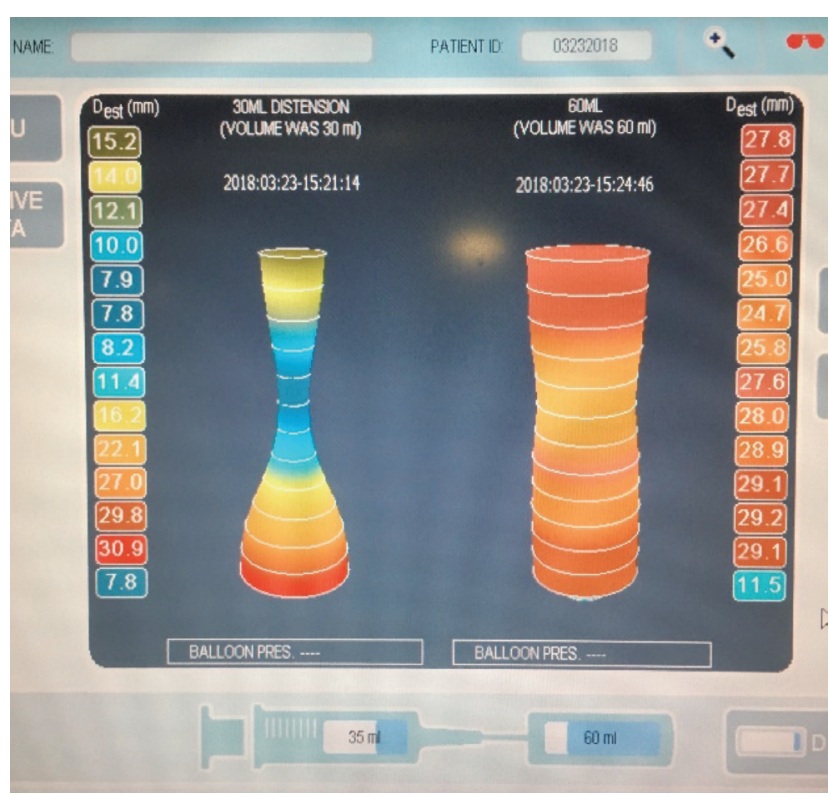

Figure 4. Impedance-planimetry-guided achalasia dilation.

backs that prevent it from being a frontline treatment [12]. The first is its transient effectiveness. Despite good early results, the effect substantially fades over time, with $60 \%$ of patients having recurrent dysphagia at 1 year and $80 \%$ at 2 years. The second is that intramuscular Botox injections cause submucosal fibrosis, which interferes with subsequent definitive treatments [13]. For these reasons, Botox is generally recommended only for patients who are poor medical candidates for definitive treatment or as a transient palliation for very acute cases (e.g., total outlet obstruction in patients in whom timely, definitive treatment is not possible) [14].

\section{Pneumatic dilation}

The popularity of pneumatic dilation (PD) has waxed and waned for several decades. The technique involves placement of a fixed-diameter, high-pressure dilating balloon across the LES, usually under fluoroscopic visualization. Dilation is performed until the balloon waist is seen to disappear. The balloons are typically 30 or 35 $\mathrm{mm}$ in diameter, with most current protocols calling for dilation with the $30-\mathrm{mm}$ balloon followed by the $35-\mathrm{mm}$ balloon if adequate results are not obtained [15]. Early results are good, with $70 \%$ of patients experiencing a substantial relief of dysphagia at 6 months after a mean of two dilation episodes [16]. However, late-term follow-up has documented decreasing success over time, with only $36 \%$ of patients still having dysphagia relief after 20 years [17]. Several studies have shown better results with PD in patients over 40 years of age [18] and worse outcomes in patients with Chicago type III achalasia (60\% vs. 93\% Chicago I/II) [19]. The risk of esophageal perforation is $3 \%$ to $6 \%$, which is the major reason why PD remains controversial in terms of its acceptance [20], although most of the perforations occurring with PD can be treated conservatively [21]. Impedance planimetry using a proprietary $30-\mathrm{mm}$ balloon allows achalasia dilation without fluoroscopy and under very controlled conditions. It may rejuvenate interest in PD (Fig. 4).

\section{Laparoscopic Heller myotomy}

A minimally invasive Heller myotomy (HM) involving a thoracoscopic approach was first described by Pellegrini et al. [22]. Yet, while the thoracoscopic approach replicated the classic open surgical method it was quickly abandoned due to poor results [23]. Subsequently, excellent results and great patient benefit were obtained using a laparoscopic approach, which quickly became the gold standard surgical treatment [24,25]. A landmark study by Richards et al. [26] from Vanderbilt University (Nashville, TN, USA), confirmed the need to add a partial fundoplication to the myotomy to minimize the incidence of iatrogenic GERD.

Laparoscopic HM has become a fairly well-standardized procedure: a five-laparoscopic port approach is used, with mobilization of at least the anterior $180^{\circ}$ of the gastroesophageal junction and distal esophagus ( $360^{\circ}$ if a Toupet is planned) followed by a full-thickness myotomy that is extended to the distal esophagus at least until the hiatus of the diaphragm. We tend to avoid extension of the myotomy into the free mediastinum due to the risk of late-term saccular dilation of the myotomy site. The traditional $2-\mathrm{cm}$ extension of the myotomy onto the anterior stomach wall has been challenged by a prospective study by Oelschlager et al. [27], which showed better outcomes with a 3 -cm extension.

The type of fundoplication that is added following the myotomy remains controversial. The Dor anterior $180^{\circ}$ wrap and the Toupet $270^{\circ}$ posterior wrap are the most commonly used, but there are rare anecdotal reports advocating a $360^{\circ}$ Nissen fundoplication. Among the arguments for the Dor procedure are that it re- 


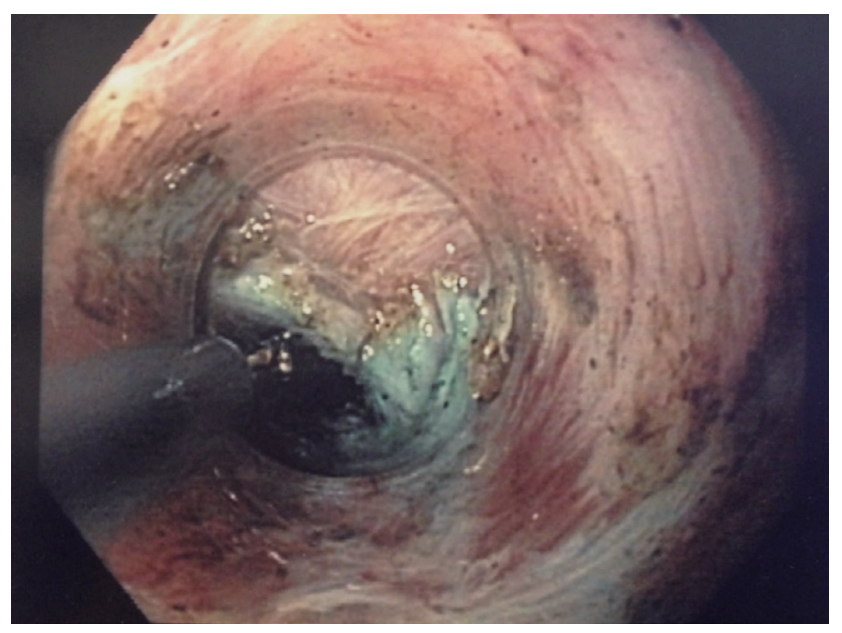

Figure 5. Circular muscle myotomy during a per-oral endoscopic myotomy.

quires less hiatal dissection and covers the exposed mucosa of the myotomy site, which may offer protection in case of perforation. Advocates of the Toupet procedure claim that its $270^{\circ}$ wrap prevents reflux more effectively, and that fixation to the edges of the myotomy helps to prevent the myotomy site from healing in a closed position. However, there are as yet no studies providing conclusive support for one or the other procedure, and the choice of fundoplication continues to be a matter of the surgeon's preference $[28,29]$.

\section{Per-oral endoscopic myotomy}

POEM is the offspring of the natural orifice transenteric endoscopic surgery (NOTES) procedure adopted in the late 200os. In seeking a safe exit strategy from the gastrointestinal tract by sub-mucosal tunneling, Pasricha et al. [30] discovered that they could visualize the circular muscle of the LES clearly during tunneling, and proposed that achalasia myotomy would be feasible. They presented a proof of concept in four pigs in 2009 [30]. Inoue et al. [31], a surgical endoscopist, first applied this concept to humans in 2010 and coined the term "POEM."

POEM utilizes the skills and tools common to advanced surgical endoscopy techniques, such as endoscopic sub-mucosal dissection. The procedure is designed according to the manometry findings, with a short myotomy for Chicago types I and II and a long myotomy for Chicago type III and spastic disorders. A mucosal lift with methylene blue saline is created $3 \mathrm{~cm}$ proximal to the planned start of the myotomy and a longitudinal incision extending to the muscularis propria is made. An endoscope fitted with a dissecting cap is introduced into this submucosal plane, after which a tunnel is dissected down to and across the LES and 2 to $3 \mathrm{~cm}$ onto the proximal wall of the stomach. Once the tunnel is created, the endoscope is pulled back to the proximal tunnel and the myotomy is started by selectively dividing the circular muscle fibers (Fig. 5). At completion, the mucosal opening is closed using hemostatic clips.

Over the last 10 years, POEM has been rapidly adopted and is now the primary form of treatment at the majority of high-volume achalasia centers. The literature contains an enormous number of studies, both from single centers describing short-term outcomes, including some series with more than 1,000 patients [32], and from multiple centers reporting 1- and 2-year [33,34] and even 5-year [35] outcomes. Together, these reports have confirmed the safety of POEM, as major operative and postoperative complications are rare, as is the need for conversion to a surgical approach. No studies reporting POEM-related mortality have been published to date, although there are anecdotal reports. Summarizing the literature on POEM, successful relief of dysphagia by POEM, as defined by an Eckhardt score $<3$, is $>90 \%$ after short-term and $>80 \%$ after long-term follow-up. The incidence of iatrogenic GERD following POEM in the early days of the procedure varied widely, ranging from no reflux to an incidence of almost 50\% [36-38]. As descriptions of GERD symptoms following any type of achalasia treatment are absolutely unreliable [39], the most reliable data are those obtained by $\mathrm{pH}$ monitoring. Based on several series reporting objectively determined reflux, the incidence of post-POEM GERD is between $30 \%$ and $40 \%$ [40]. The incidence of patients whose GERD symptoms cannot be controlled medically and require antireflux surgery is very low.

To date, there have been no randomized prospective studies comparing POEM with other achalasia treatments. This is due, in part, to the rarity of achalasia in the population and to the fact that non-randomized results are highly equivalent to the best endoscopic or surgical treatment, such that powering such a randomization is a daunting proposition. Retrospective comparisons between, in particular, laparoscopic HM and 
POEM [41] have shown similar rates of complication and a similar safety profile, slightly better relief of dysphagia, and an equal or slightly higher incidence of reflux or reflux symptoms. Again, the differences in these compiled studies between dysphagia relief and GERD incidence are so small, and the disease so rare, that an adequately powered randomized study that truly defines the best treatment cannot reasonably be expected.

\section{EMERGING TREATMENTS}

As with all chronic non-curable diseases, achalasia continues to generate new ideas aimed at addressing the symptoms or even the disease.

De Palma et al. [42] first described the use of esophageal stents in 1998 and, in the following years, have sporadically updated their experience. Initially, esophageal stenting was specifically indicated for patients with end-stage disease that had not responded to other treatments. However, several groups have since reported on stenting as a primary treatment for achalasia based on two general strategies: long-term (months) implantation of a regular-sized stent ( 20 to $25 \mathrm{~mm}$ ) or short-term (<1 week) implantation of a large-diameter (30-mm) stent. The former strategy has been largely abandoned due to high complication rates (migrations and serious erosions) and poor long-term results (49\% at 36 months) $[43,44]$. The results obtained using a specially designed 30-mm stent implanted for $<1$ week have been better, with lower migration rates (6\%) and remission rates of $>80 \%$ at up to 2 years follow-up. However these larger stents are associated with significant rates of chest pain [45].

Other active investigations still in the basic science research phase include neural cell transplantation [46] and electrical stimulation $[47,48]$. Both are many years away from clinical application. Thus, for now, palliation by various methods of LES disruption is the most effective strategy.

\section{CONCLUSIONS}

Achalasia as a rare esophageal motility disorder which, while seldom lethal, still represents tremendous pa- tient morbidity and distress. While the etiology of the disease is poorly understood, there are a wide spectrum of moderately effective palliative treatments ranging from endoscopic to open surgical treatments. Today, the current "gold standard" treatment of laparoscopic heller myotomy with partial fundoplication is being overtaken by endoscopic myotomy (POEM) which has a ten year history of safety and efficacy. The issue of post procedure GERD, a problem with pneumatic dilatation and surgical myotomy, is again a topic of concern as its incidence is somewhat higher following POEM. This indicates that there is still research remaining to be done on achalasia as a disease.

\section{Conflict of interest}

No potential conflict of interest relevant to this article was reported.

\section{REFERENCES}

1. Spiess AE, Kahrilas PJ. Treating achalasia: from whalebone to laparoscope. JAMA 1998;280:638-642.

2. Sadowski DC, Ackah F, Jiang B, Svenson LW. Achalasia: incidence, prevalence and survival. A population-based study. Neurogastroenterol Motil 2010;22:e256-e261.

3. Cecere MC, Rodriguez-Planes LI, Vazquez-Prokopec GM, Kitron U, Gurtler RE. Community-based surveillance and control of Chagas disease vectors in remote rural areas of the Argentine Chaco: a five-year follow-up. Acta Trop 2019;191:108-115.

4. Gockel I, Bohl JR, Doostkam S, Eckardt VF, Junginger T. Spectrum of histopathologic findings in patients with achalasia reflects different etiologies. J Gastroenterol Hepatol 2006;21:727-733.

5. Kurnaz E, Duminuco P, Aycan Z, et al. Clinical and genetic characterisation of a series of patients with triple $A$ syndrome. Eur J Pediatr 2018;177:363-369.

6. Boeckxstaens GE. Novel mechanism for impaired nitrergic relaxation in achalasia. Gut 2006;55:304-305.

7. Hu Y, Li M, Lu B, Meng L, Fan Y, Bao H. Esophageal motility after peroral endoscopic myotomy for achalasia. J Gastroenterol 2016;51:458-464.

8. Taft TH, Carlson DA, Triggs J, et al. Evaluating the reliability and construct validity of the Eckardt symptom score as a measure of achalasia severity. Neurogastroen- 
terol Motil 2018;30:e13287.

9. Kahrilas PJ, Bredenoord AJ, Fox M, et al. The Chicago Classification of esophageal motility disorders, v3.o. Neurogastroenterol Motil 2015;27:160-174.

10. Lee H, Chung H, Lee TH, et al. Therapeutic outcome of achalasia based on high-resolution manometry: a Korean multicenter study. Am J Ther 2019;26:e452-e461.

11. Pasricha PJ, Ravich WJ, Hendrix TR, Sostre S, Jones B, Kalloo AN. Intrasphincteric botulinum toxin for the treatment of achalasia. N Engl J Med 1995;332:774-778.

12. Zaninotto G, Vergadoro V, Annese V, et al. Botulinum toxin injection versus laparoscopic myotomy for the treatment of esophageal achalasia: economic analysis of a randomized trial. Surg Endosc 2004;18:691-695.

13. Horgan S, Hudda K, Eubanks T, McAllister J, Pellegrini CA. Does botulinum toxin injection make esophagomyotomy a more difficult operation? Surg Endosc 1999;13:576-579.

14. Zaninotto G, Bennett C, Boeckxstaens G, et al. The 2018 ISDE achalasia guidelines. Dis Esophagus 2018;31:doyo71.

15. Kadakia SC, Wong RK. Pneumatic balloon dilation for esophageal achalasia. Gastrointest Endosc Clin N Am 2001;11:325-346.

16. Felix VN. Results of pneumatic dilation in treating achalasia: predictive factors. Ann N Y Acad Sci 2018;1434:124131.

17. Muller M, Keck C, Eckardt AJ, et al. Outcomes of pneumatic dilation in achalasia: extended follow-up of more than 25 years with a focus on manometric subtypes. J Gastroenterol Hepatol 2018;33:1067-1074.

18. Farhoomand K, Connor JT, Richter JE, Achkar E, Vaezi MF. Predictors of outcome of pneumatic dilation in achalasia. Clin Gastroenterol Hepatol 2004;2:389-394.

19. Lee JY, Kim N, Kim SE, et al. Clinical characteristics and treatment outcomes of 3 subtypes of achalasia according to the Chicago classification in a tertiary institute in Korea. J Neurogastroenterol Motil 2013;19:485-494.

20. Ghoshal UC, Karyampudi A, Verma A, et al. Perforation following pneumatic dilation of achalasia cardia in a university hospital in northern India: a two-decade experience. Indian J Gastroenterol 2018;37:347-352.

21. Scatton O, Gaudric M, Massault PP, Chaussade S, Houssin $\mathrm{D}$, Dousset B. Conservative management of esophageal perforation after pneumatic dilatation for achalasia. Gastroenterol Clin Biol 2002;26:883-887.

22. Pellegrini C, Wetter LA, Patti M, et al. Thoracoscop- ic esophagomyotomy. Initial experience with a new approach for the treatment of achalasia. Ann Surg 1992;216:291-296.

23. Patti MG, Arcerito M, De Pinto M, et al. Comparison of thoracoscopic and laparoscopic Heller myotomy for achalasia. J Gastrointest Surg 1998;2:561-566.

24. Rosemurgy A, Downs D, Luberice K, et al. Laparoscopic Heller myotomy with anterior fundoplication improves frequency and severity of symptoms of achalasia, regardless of preoperative severity determined by esophagography. Am Surg;84:165-173.

25. Asti E, Sironi A, Lovece A, et al. Health-related quality of life after laparoscopic Heller myotomy and Dor fundoplication for achalasia. Surgery 2017;161:977-983.

26. Richards WO, Torquati A, Holzman MD, et al. Heller myotomy versus Heller myotomy with Dor fundoplication for achalasia: a prospective randomized double-blind clinical trial. Ann Surg 2004;240:405-412.

27. Oelschlager BK, Chang L, Pellegrini CA. Improved outcome after extended gastric myotomy for achalasia. Arch Surg 2003;138:490-495.

28. Torres-Villalobos G, Coss-Adame E, Furuzawa-Carballeda J, et al. Dor vs Toupet fundoplication after laparoscopic Heller myotomy: long-term randomized controlled trial evaluated by high-resolution manometry. J Gastrointest Surg 2018;22:13-22.

29. Kurian AA, Bhayani N, Sharata A, Reavis K, Dunst CM, Swanstrom LL. Partial anterior vs partial posterior fundoplication following transabdominal esophagocardiomyotomy for achalasia of the esophagus: meta-regression of objective postoperative gastroesophageal reflux and dysphagia. JAMA Surg 2013;148:85-90.

30. Pasricha PJ, Hawari R, Ahmed I, et al. Submucosal endoscopic esophageal myotomy: a novel experimental approach for the treatment of achalasia. Endoscopy 2007;39:761-764.

31. Inoue H, Minami H, Kobayashi Y, et al. Peroral endoscopic myotomy (POEM) for esophageal achalasia. Endoscopy 2010;42:265-271.

32. Bechara R, Onimaru M, Ikeda H, Inoue H. Per-oral endoscopic myotomy, 1000 cases later: pearls, pitfalls, and practical considerations. Gastrointest Endosc 2016;84:330338.

33. Sharata AM, Dunst CM, Pescarus R, et al. Peroral endoscopic myotomy (POEM) for esophageal primary motility disorders: analysis of 100 consecutive patients. J Gastro- 
intest Surg 2015;19:161-170.

34. Werner YB, Costamagna G, Swanstrom LL, et al. Clinical response to peroral endoscopic myotomy in patients with idiopathic achalasia at a minimum follow-up of 2 years. Gut 2016;65:899-906.

35. Teitelbaum EN, Dunst CM, Reavis KM, et al. Clinical outcomes five years after POEM for treatment of primary esophageal motility disorders. Surg Endosc 2018;32:421-427.

36. von Renteln $\mathrm{D}$, Inoue $\mathrm{H}$, Minami $\mathrm{H}$, et al. Peroral endoscopic myotomy for the treatment of achalasia: a prospective single center study. Am J Gastroenterol 2012;107:411417.

37. Stavropoulos SN, Brathwaite CE, Iqbal S, et al. 509 P.O.E.M. (peroral endoscopic myotomy), a U.S. gastroenterologist perspective: initial 2 year experience. Gastrointest Endosc 2012;75(4 Suppl):AB149.

38. Hungness ES, Sternbach JM, Teitelbaum EN, Kahrilas PJ, Pandolfino JE, Soper NJ. Per-oral endoscopic myotomy (POEM) after the learning curve: durable long-term results with a low complication rate. Ann Surg 2016;264:508-517.

39. Lacy BE, Weiser K, Chertoff J, et al. The diagnosis of gastroesophageal reflux disease. Am J Med 2010;123:583-592.

40. Sanaka MR, Thota PN, Parikh MP, et al. Peroral endoscopic myotomy leads to higher rates of abnormal esophageal acid exposure than laparoscopic Heller myotomy in achalasia. Surg Endosc 2019;33:2284-2292.

41. Zhang Y, Wang H, Chen X, et al. Per-oral endoscopic myotomy versus laparoscopic Heller myotomy for achalasia: a meta-analysis of nonrandomized comparative studies. Medicine (Baltimore) 2016;95:e2736.

42. De Palma GD, lovino P, Masone S, Persico M, Persico G. Self-expanding metal stents for endoscopic treatment of esophageal achalasia unresponsive to conventional treatments. Long-term results in eight patients. Endoscopy 2001;33:1027-1030.

43. Sioulas AD, Malli C, Dimitriadis GD, Triantafyllou K. Self-expandable metal stents for achalasia: thinking out of the box! World J Gastrointest Endosc 2015;7:45-52.

44. Zhao H, Wan XJ, Yang CQ. Comparison of endoscopic balloon dilation with metal stent placement in the treatment of achalasia. J Dig Dis 2015;16:311-318.

45. Dai J, Shen Y, Li X, Gao Y, Song Y, Ge Z. Long-term efficacy of modified retrievable stents for treatment of achalasia cardia. Surg Endosc 2016;30:5295-5303.

46. Metzger M, Caldwell C, Barlow AJ, Burns AJ, Thapar N. Enteric nervous system stem cells derived from human gut mucosa for the treatment of aganglionic gut disorders. Gastroenterology 2009;136:2214-2225.

47. Khajanchee YS, VanAndel R, Jobe BA, Barra MJ, Hansen PD, Swanstrom LL. Electrical stimulation of the vagus nerve restores motility in an animal model of achalasia. J Gastrointest Surg 2003;7:843-849.

48. Zhang L, Zhao W, Zhao C, Jin H, Wang B, Wang B. Study on effects of electrical stimulation on rabbit esophageal body motility in vivo. Physiol Res 2018;67:275-282. 